\title{
Inter- and intraspecific variability of morphological and molecular characters in Allothrombium species, with special reference to Allothrombium fuliginosum
}

\author{
Joanna Mąkol ${ }^{1}$ (D) - Alireza Saboori² ${ }^{(D} \cdot$ Magdalena Felska $^{1}$ (D)
}

Received: 20 March 2019 / Accepted: 24 June 2019 / Published online: 10 July 2019

(c) The Author(s) 2019

\begin{abstract}
Morphology-based identification of Allothrombium spp., in view of the limited knowledge of intraspecific variation, hinders the recognition of species borders and affects the views on the actual distribution of species. Therefore, identification will benefit from reference to molecular methods. The separate species identity of specimens putatively representing Allothrombium fuliginosum and A. pulvinum, both reported as widely distributed in the Palaearctic region and considered as potential biological control agents, was checked using morphological and molecular analyses. The representatives of various Allothrombium spp. collected in the Palaearctic were included in the analysis in order to ascertain the distance between species. The results of the morphological examination, supported by statistical inference, along with the comparison of COI and/or ITS2 sequences, weaken the hypothesis of synoccurrence of both species in the Palaearctic region. Hence, we hypothesize that A. fuliginosum is widely distributed in the Palaearctic, whereas A. pulvinum should be regarded a Nearctic species.
\end{abstract}

Keywords Allothrombium · Palaearctic · Morphology $\cdot$ COI $\cdot$ ITS2 $\cdot$ Allothrombium pulvinum

Electronic supplementary material The online version of this article (https://doi.org/10.1007/s1049 3-019-00400-5) contains supplementary material, which is available to authorized users.

Magdalena Felska

magdalena.felska@upwr.edu.pl

Joanna Mąkol

joanna.makol@upwr.edu.pl

Alireza Saboori

saboori@ut.ac.ir

1 Department of Invertebrate Systematics and Ecology, Wrocław University of Environmental and Life Sciences, Kożuchowska 5B, 51-631 Wrocław, Poland

2 Jalal Afshar Zoological Museum, Department of Plant Protection, Faculty of Agriculture, University of Tehran, Karaj, Iran 


\section{Introduction}

Among Trombidioidea (Acariformes: Parasitengona), the representatives of Allothrombium have been indicated the most effective agents in biological control of pests of crops and orchards (e.g. Welbourn 1983; Zhang 1992, 1998), with high potential in integrated pest management. Accurate assessment of their success as control agents is difficult, however, in view of insufficient knowledge of the taxonomy, biology and ecology of species (Muñoz-Cárdenas et al. 2015). Limited knowledge of intraspecific variation of morphological (qualitative and quantitative) traits in active developmental stages of Allothrombium, hinders the inference on actual species limits and, in consequence, affects the views on distribution patterns. A reference to molecular methods would contribute to verification of the status of presently distinguished, nominal taxa. Several members of Allothrombium have been known from single or few specimens representing only one instar. The description of heteromorphic instars (both larvae and active post-larval forms) has been provided for seven species, i.e. as few as $10 \%$ of all nominal taxa assigned to the genus (Moss 1962a, b; Robaux 1974; Robaux and Aeschlimann 1987; Zhang and Xin 1989b; Saboori and Zhang 1997; Saboori and Kamali 2000; Wohltmann and Mąkol 2009; Mąkol and Wohltmann 2012), whereas only for Allothrombium fuliginosum (Hermann), Allothrombium ovatum Zhang and Xin (known exclusively from larvae) and Allothrombium pulvinum Ewing substantial material was examined, encompassing long series of specimens (e.g. Mąkol 2005; Zhang 2010).

Both A. fuliginosum and A. pulvinum are among the most often listed members of the genus, associated with crops and orchards (e.g. Chen and Zhang 1991; Zhang and Chen 1993; Zhang et al. 1993; Zhang and Faraji 1994; Zhang 1998). Allothrombium fuliginosum, with the type locality in Poland (Mąkol 2005), was subject to detailed analyses, including data on morphology and life cycle (Henking 1882; Robaux 1974; Mąkol 2005) and is considered as widely distributed in the Western Palaearctic (Mąkol and Wohltmann 2012). A comprehensive treatise of A. pulvinum, supplemented with information on its biology and distribution, was provided by Zhang and Xin (1989a), Zhang and Faraji (1994), Saboori and Zhang (1996) and Zhang (1996). The data on occurrence of A. pulvinum are widely scattered in the Holarctic. The species, originally described from Marshall, Illinois, USA (Ewing 1917), has been recorded also from several countries in the Palaearctic region (Mąkol and Wohltmann 2012; Šundić and Pajović 2012). The actual distribution of both $A$. fuliginosum and A. pulvinum, however, may depart from the one reported in the literature, due to the still unresolved limits between the species.

The problem of separate identity of A. pulvinum and A. fuliginosum, already depicted by Zhang and Xin (1992), Mąkol (2005) and Wohltmann and Mąkol (2009), is especially crucial in view of their reported overlapping distribution in the Palaearctic and is further intensified by the recurrent records on A. pulvinum from the area in question. For the relatively well studied countries, with respect to fauna of Allothrombium, such as China, Iran and Poland (e.g. Zhang 1988; Zhang and Faraji 1994; Mąkol 2005; Khalili Mahani et al. 2009), the synoccurrence of both species has not been confirmed. The latter may suggest the limits of latitudinal distribution of both species falling on boundaries between the Western and Eastern Palaearctic or between the Palaearctic and Nearctic Region. On the other hand, given the overall scarcity of morphological differences between A. fuliginosum and A. pulvinum (for details see Zhang and Xin 1989a, b; Zhang and Faraji 1994), which pertain predominantly to larvae, the question of the synoccurrence of both species in the Palaearctic and of their overall separate identity, entails the necessity to appeal to other evidence. 
The present study aims to discover character traits that differentiate between specimens assigned to A. fuliginosum and A. pulvinum originating from the Palaearctic region, based on morphological and molecular data [cytochrome $\mathrm{c}$ oxidase subunit I (COI) and nuclear internal transcribed spacer of rDNA (ITS2)].

\section{Materials and methods}

The material included representatives of active life instars (larvae and post-larval forms) of Allothrombium spp. collected at various localities within the recorded distribution of $A$. fuliginosum and A. pulvinum in the Palaearctic (for purpose of the present study, the name 'A. pulvinum' is given in single quotation marks, in order to stress the Palaearctic origin of specimens assigned to A. pulvinum based on preliminary identification of the material originating from Europe and Asia, and to distinguish them from North American representatives of the species). For specification and affiliation of the material see Table 1.

Larvae were also obtained from cultures in climatic chambers (material from Poland: $80 \% \mathrm{RH}, \mathrm{L} 12\left(22^{\circ} \mathrm{C}\right)$ :D12 $\left(15^{\circ} \mathrm{C}\right)$ photo-thermoperiod; material from Iran: $80 \% \mathrm{RH}, \mathrm{L} 16$ $\left(27{ }^{\circ} \mathrm{C}\right)$ :D8 $\left(22{ }^{\circ} \mathrm{C}\right)$ photo-thermoperiod) started with field-collected, ovigerous females preliminarily assigned to A. fuliginosum (specimens from Poland) and 'A. pulvinum' (specimens from Iran).

Thirty larvae and 15 specimens representing active post-larval forms of A. fuliginosum and of 'A. pulvinum' were subjected to morphometric analysis. Damaged or obscure structures were excluded from the analysis. Due to the presence of three pairs of genital acetabula in the representatives of active post-larval forms of Allothrombium spp. (contrary to two pairs in deutonymphs and three in adults of most Trombidioidea), and in order to avoid misinterpretation of instars, all individuals representing active post-larval stages were pooled together. Morphological analysis covered 54 measurable traits of larvae and 52 of active post-larval forms. Additionally, the meristic characters of larvae were also considered in order to ascertain the constancy of character states. Measurements (in $\mu \mathrm{m}$ ) were made under Nikon Eclipse E600 and 80i with differential interference contrast and NISElements BR software. Shapiro-Wilk and Mann-Whitney U tests to check for normality and to compare sample means, as well as cluster analysis (K-means clustering), aiming at the discovery of groups representing potentially distinct species, were made using STATISTICA v.13.1 (Dell Software, Round Rock, TX, USA). The terminology and abbreviations follow Mąkol (2005).

In morphology-based identification of specimens assigned to A. pulvinum we refer to Ewing (1917), Zhang and Xin (1989b, 1992) and Zhang and Faraji (1994). Due to some incongruence in characteristics of the larva of A. fuliginosum provided by various authors (e.g. Henking 1882; Hirst 1926; Feider 1951), as already pointed at by Zhang and Xin (1992) and confirmed during our recent studies, we refer to the detailed description of the larva provided by Robaux (1974) and of larval and active post-larval forms by Mackol (2005). The identification of other Allothrombium spp. was based on original descriptions (for references see Mąkol and Wohltmann 2012).

Eighteen specimens of Allothrombium spp. (Table 1) were designed for molecular examination. Altogether, 25 sequences were obtained, including 18 of COI and seven of ITS2 (including one partial sequence, forward strain only). For DNA extraction and isolation protocol see Moniuszko et al. (2015). Amplification of the COI barcode region was performed using degenerate primers: bcdF04 (5'-CATTTTCHACTAAYCATAARGAT 


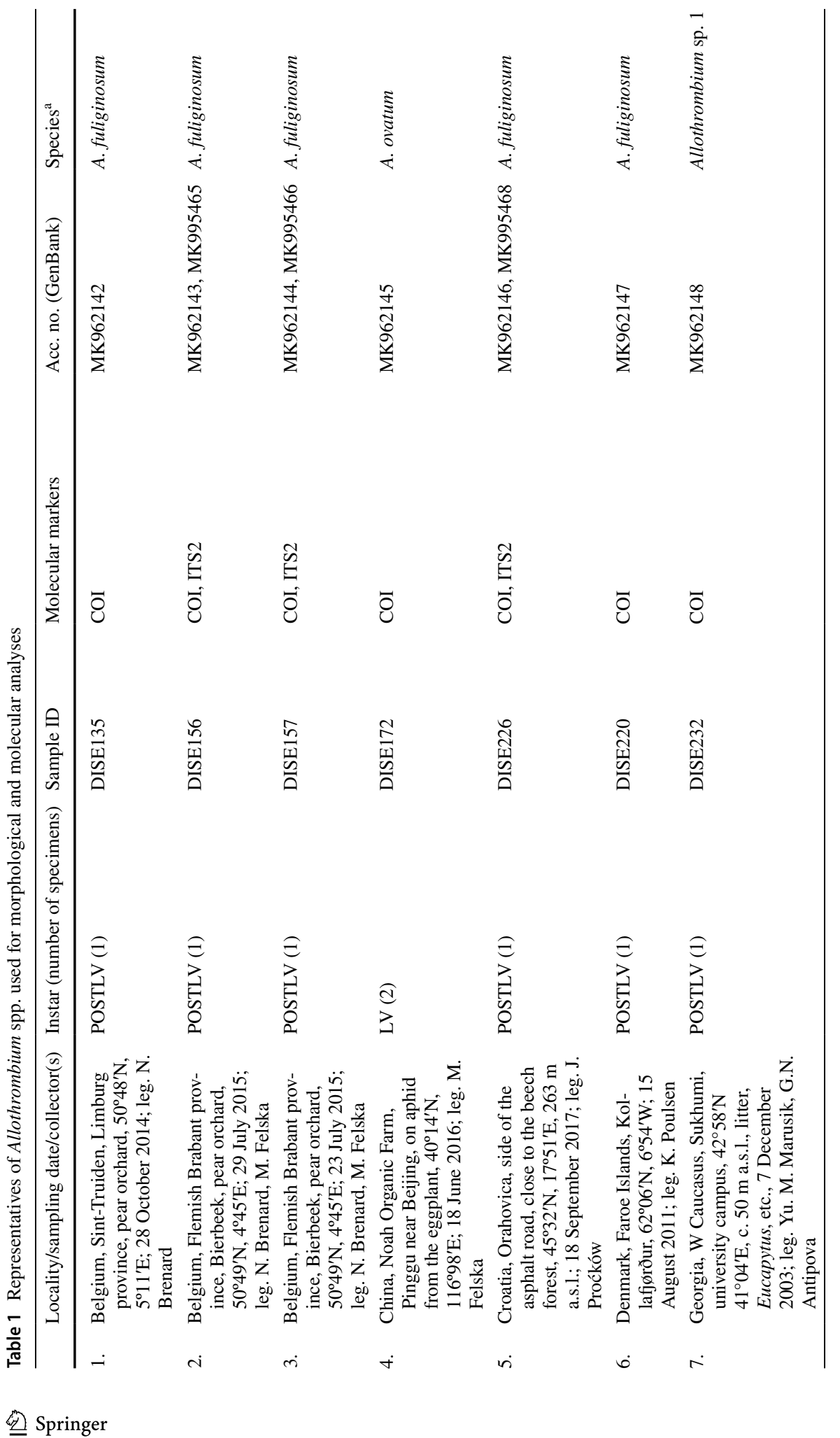




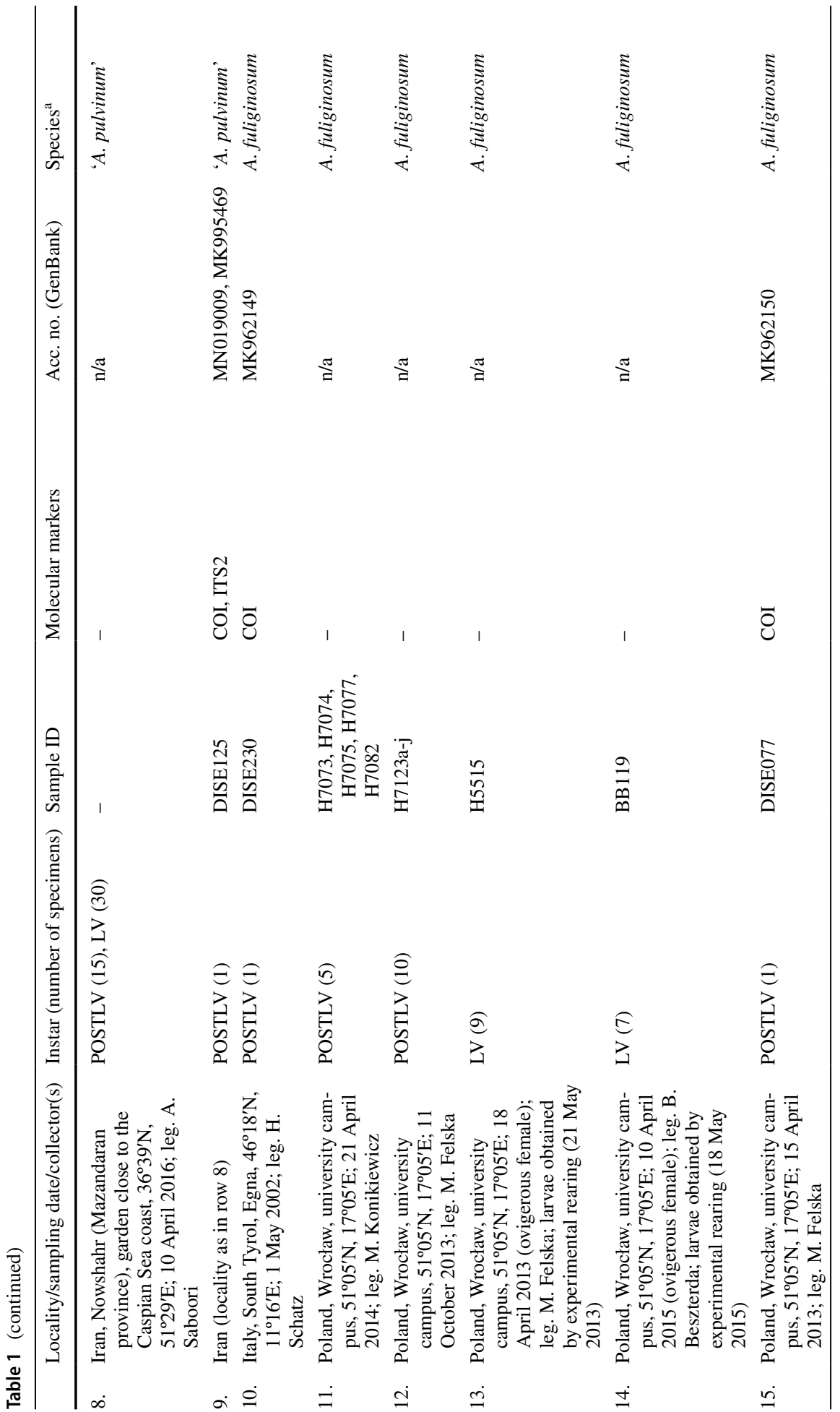




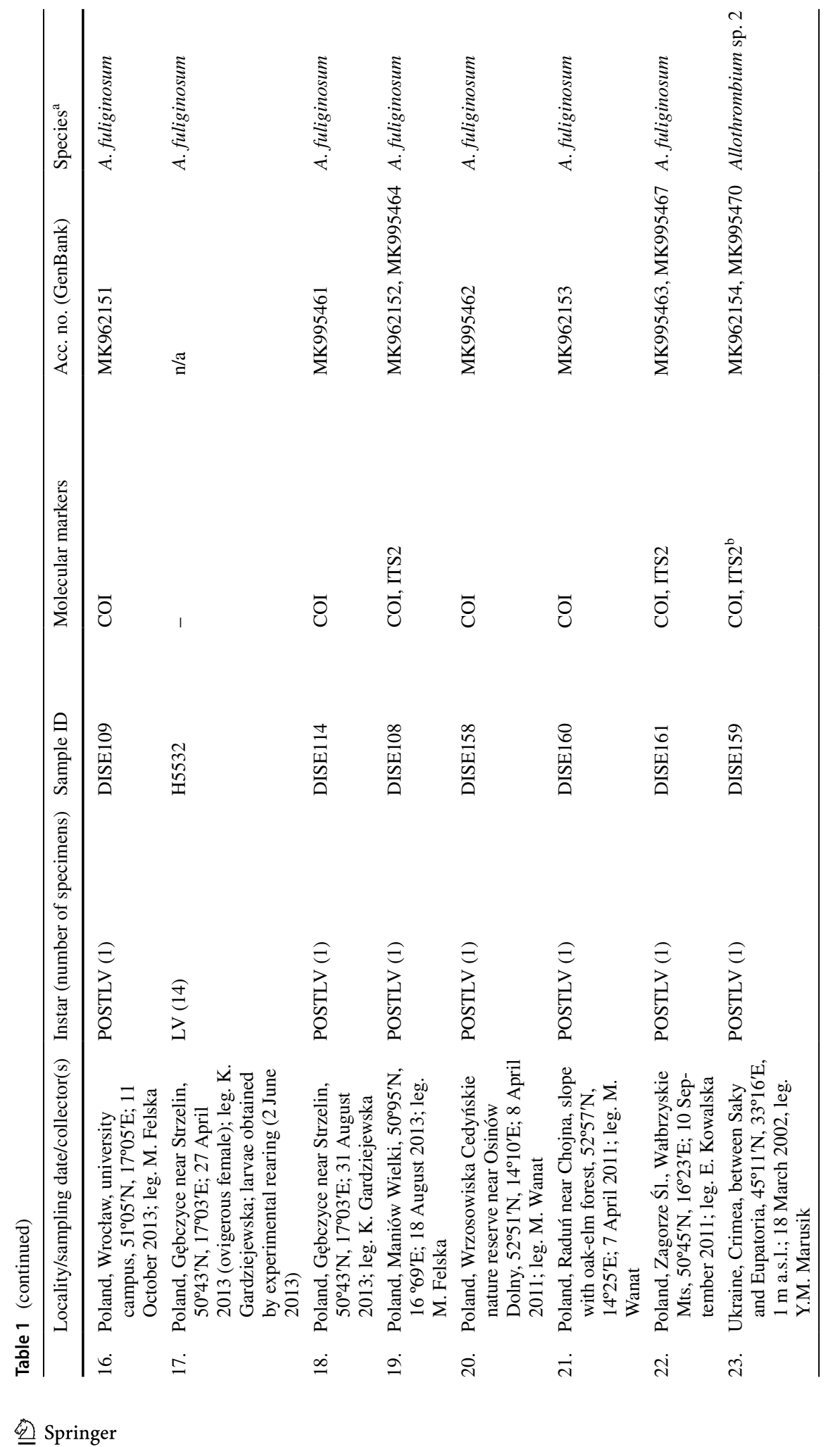




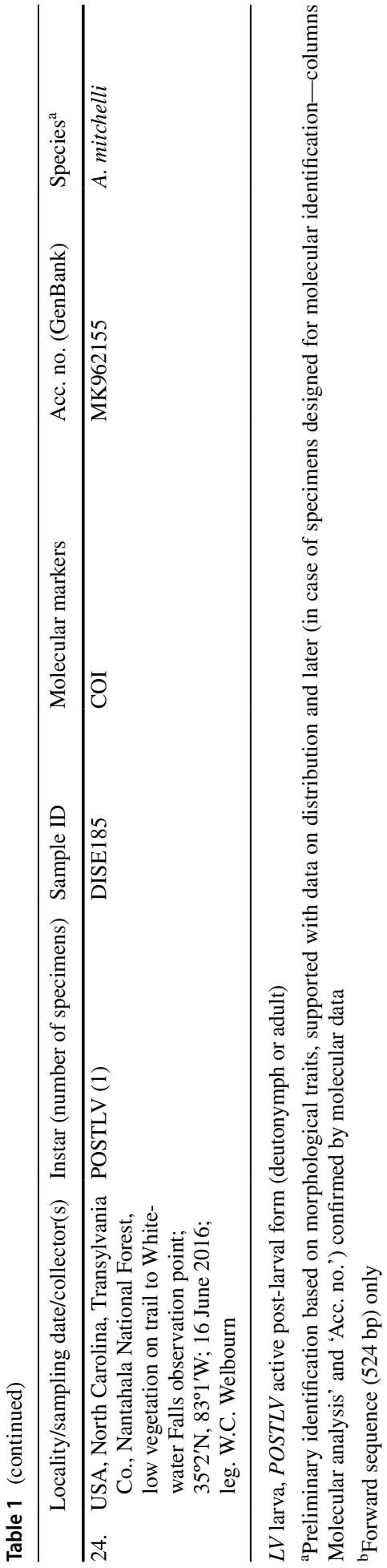


ATTGG-3') and bcdR04 (5'-TATAAACYTCDGGATGNCCAAAAAA-3') (Dabert et al. 2010) in the following thermocycling conditions: $95^{\circ} \mathrm{C}$ for $3 \mathrm{~min}$-initial denaturation; $95^{\circ} \mathrm{C}$ for $20 \mathrm{~s}, 46^{\circ} \mathrm{C}$ for $20 \mathrm{~s}, 72^{\circ} \mathrm{C}$ for $45 \mathrm{~s}-40$ cycles; $72{ }^{\circ} \mathrm{C}$ for $7 \mathrm{~min}$-final extending. Amplification of the ITS2 was performed using the following primers: LC1 (5'-CGAGTA TCGATGAAGAACGCAGC-3') and HC2 (5'-ATATGCTTAAGTTCAGCGGG-3') located between the 5.8S and 28S rDNA flanking regions, respectively (Navajas et al. 1992, 1994; Khalili Mahani et al. 2009). PCR conditions for the ITS2 fragment were as follows: $95{ }^{\circ} \mathrm{C}$ for 3 min-initial denaturation; $95{ }^{\circ} \mathrm{C}$ for $45 \mathrm{~s}, 53{ }^{\circ} \mathrm{C}$ for $45 \mathrm{~s}, 72{ }^{\circ} \mathrm{C}$ for $45 \mathrm{~s}-35$ cycles; $72{ }^{\circ} \mathrm{C}$ for $7 \mathrm{~min}$-final extending. The sequences are deposited in the GenBank under the following accession numbers: MK962142-MK962155, MK995461-MK995463, MN019009 and MK995464-MK995470 for COI and ITS2, respectively (for sample identification see Table 1). Voucher specimens are stored in the Department of Invertebrate Systematics and Ecology, Wrocław University of Environmental and Life Sciences (Wrocław, Poland). In case of single specimens originating from Crimea and Georgia, the identification was limited to genus level; however, the separate specific affiliation of both specimens, temporarily assigned to Allothrombium sp. 1 and Allothrombium sp. 2, as well as their distinctness to other Allothrombium spp. considered in the survey, could be confirmed by molecular analyses.

In addition to the sequences obtained in the present study and for purpose of comparison, the ITS2 sequences (FJ263064.1-FJ263089.1) of specimens assigned to A. pulvinum by Khalili Mahani et al. (2009) were retrieved from the GenBank. Multiple alignment was done with the ClustalW algorithm, implemented in MEGA7 package (Kumar et al. 2016), using the default parameters (gap opening penalty: 15 , gap extension penalty: 6.66 , both for pairwise and multiple alignment). All the sequences of the same gene region were trimmed to the same length to allow comparisons within each dataset. Distance between sequences was calculated using the Kimura 2-parameter model (K2P) (Kimura 1980). Standard error estimates were obtained by a bootstrap procedure (1000 replicates). Phylogenetic trees were constructed using maximum likelihood (MLE) and Bayesian (BE) estimates. MLE was based on the Kimura 2-parameter model and bootstrap analysis with 1000 replicates in MEGA7. Information on haplotype data for ITS2 sequences was estimated using the DnaSP software package v.6.12.01 (Rozas et al. 2017). Bayesian analyses were performed with MrBayes (Huelsenbeck and Ronquist 2001) using the GTR substitution model. Markov Chain Monte Carlo (MCMC) analysis was run for 1.000 .000 generations and trees were sampled every 100 generations. The outgroup sequences (COI) were obtained from Trombidium holosericeum (Trombidiidae) (acc. no. MK995460), Podothrombium sp. (Podothrombiidae) (acc. no. MK995458), and Platytrombidium fasciatum (Microtrombidiidae) (acc. no. MK995459) in the present study, and from Milandanielia intermedia (Microtrombidiidae) (acc. no. KR633048.1; Felska and Mąkol 2015).

\section{Results}

Larvae obtained by experimental rearing from females collected in Poland (A. fuliginosum) and in Iran ('A. pulvinum') displayed high constancy of qualitative traits. No characters that would allow to assign specimens to separate taxa were discovered. The constancy of character states (values) was revealed also during comparison of quantitative (meristic) traits (fPp: 0-0-0- $\mathrm{BNN}_{2}-\mathrm{BBNNN \omega}$; fD: 2-2-6-4-4-2=20; fV: $2-2-2 \mathrm{u}-2=8$; leg I: $\operatorname{Tr}(1 \mathrm{n})-\mathrm{Fe}(5 \mathrm{n})-\mathrm{Ge}(4 \mathrm{n}, 2 \sigma, 1 \kappa)-\mathrm{Ti}(5 \mathrm{n}, 2 \varphi, 1 \kappa)-\mathrm{Ta}(16-17 \mathrm{n}, 2 \zeta, 1 \omega, 1 \varepsilon)$; leg II: 
$\operatorname{Tr}(1 \mathrm{n})-\mathrm{Fe}(4 \mathrm{n})-\mathrm{Ge}(3 \mathrm{n}, 2 \sigma, 1 \kappa)-\mathrm{Ti}(5 \mathrm{n}, 2 \varphi)-\mathrm{Ta}(13-14 \mathrm{n}, 1 \omega, 1 \varepsilon)$; leg III: $\operatorname{Tr}(1 \mathrm{n})-\mathrm{Fe}$ $(4 n)-G e(3 n, 2 \sigma)-T i(5 n)-T a(13 n)$. For one larva collected in Iran the presence of five setae on one side of the symmetry axis on femur II, and in another specimen from the same area the presence of three solenidia on one side of symmetry axis was stated. The consistency of morphological traits was observed also in relation to active post-larval forms.

The analysis of metric data obtained for larvae and active post-larval forms of A. fuliginosum and 'A. pulvinum' with the application of K-means algorithm did not result in the discovery of data groups, thus did not reveal the difference between the groups of specimens representing two potentially distinct species. However, the ranges of metric characters overlapped, both for larvae (Table 2) and active post-larval forms (Table 3) and statistically significant differences in several metric traits obtained from two potentially different species were observed (Tables 2 and 3).

The molecular analyses resulted in a positive response in case of 18 specimens representing Allothrombium spp., out of 37 designed for examination. For COI (18 sequences), the alignment resulted in obtaining sequences of $409 \mathrm{bp}(531 \mathrm{bp}$ before inclusion of the shortest sequence). In case of ITS2 (seven sequences), after aligning with the 26 sequences (920-925 bp) of 'A. pulvinum' obtained from GenBank (Khalili Mahani et al. 2009), the data block length was 514 bp ( 849 bp before final inclusion of one partial sequence).

General topologies of the phylogenetic trees inferred by MLE and BE analyses of the nucleotide COI and ITS2 datasets (consisting in 18 and seven sequences, respectively) were similar and both estimators consistently revealed the same structure of Allothrombium spp. populations. Thus, only the ML trees are presented here (Figs. 1 and 2).

The tree based on COI sequences (Fig. 1) confirmed the separate identity of specimens preliminarily assigned to distinct species based on morphology. Members of Allothrombium spp. formed an ingroup clade which was strongly supported by bootstrap value (96\%). The within-clade relationships showed an outlying sequence of clearly distinct Allothrombium ovatum (China), but also of Allothrombium mitchelli Davis (USA) + Allothrombium sp. 1 (Georgia) and of Allothrombium sp. 2 (Crimea). The clade encompassing A. fuliginosum from Belgium, Croatia, Denmark (Faroe Islands), Italy and Poland, but also 'A. pulvinum' from Iran, was nested within Allothrombium spp. clade with 94\% bootstrap support.

Eight haplotypes were detected for 33 ITS2 sequences of Allothrombium spp. (Supplementary Table S1, Fig. 2) with the overall haplotype diversity (Hd) amounting at 0.6742 . Sequences obtained for 'A. pulvinum' from Iran (Khalili Mahani et al. 2009 and present study) were assigned to haplotypes 1-5, sequences of $A$. fuliginosum from Poland, Belgium and Croatia to haplotypes 6 and 8, and sequence of Allothrombium sp. 2 from Crimea to haplotype 7 (Supplementary Table S1). All haplotypes, except no. 7, formed a clade, in which haplotypes 6 and 8 received the strongest bootstrap support (97\%) (Fig. 2).

The genetic distance (K2P) in the COI region for specimens assigned to A. fuliginosum and to 'A. pulvinum' was $0-5.3 \%$; however, lower divergence of nucleotides between haplotypes (0-3.8\%) was observed when the most departing sequence of A. fuliginosum from Belgium (DISE135) was excluded (Supplementary Table S2). The respective value of K2P calculated for 'A. pulvinum' by Khalili Mahani et al. (2009) was 0.2-2.8\% (Supplementary Table S3). The 'interspecific' distance between A. fuliginosum and 'A. pulvinum' in the $\mathrm{COI}$ region, calculated as a distance between sequences of $A$. fuliginosum from Europe and the sequence of 'A. pulvinum' from Iran (DISE125), was 1.7-4.8\% (1.7-3.8\% when the DISE135 was excluded from analysis).

The genetic distance in the COI region between clades formed by A. fuliginosum + 'A. pulvinum' and sequences of congeneric taxa was $13.3-14.7 \%$ in relation to Allothrombium 
$\stackrel{8}{E}$

政

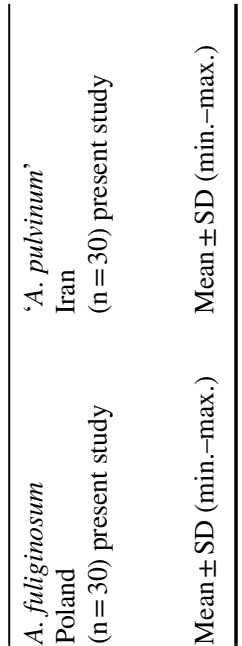

$\widehat{\circ} \odot$

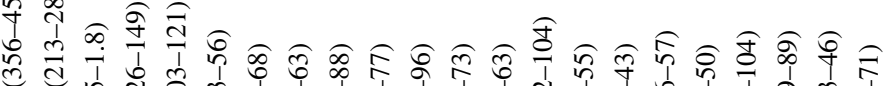

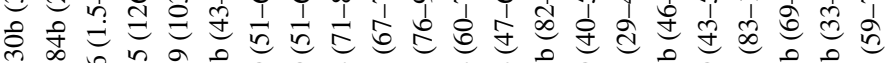

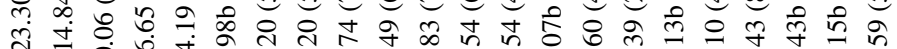

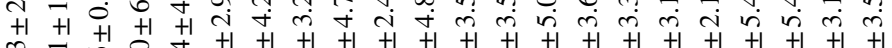

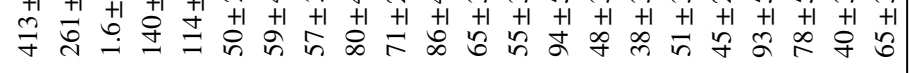

(1)

(

๙ิ

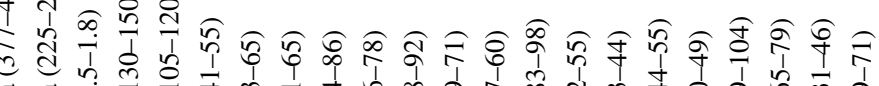
踏

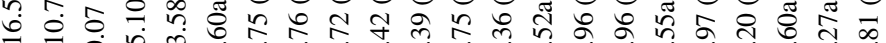

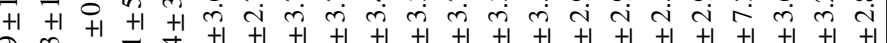

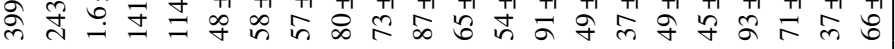

苛

莡

i

承

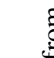

(a)

)

हี เิ

毒苟

范

窇.

$\stackrel{\frac{1}{5}}{\circ}$

至.

उै

政

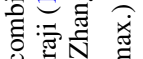

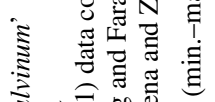

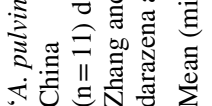

望告

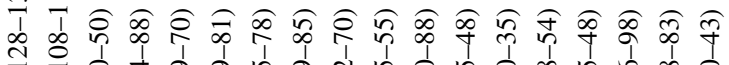

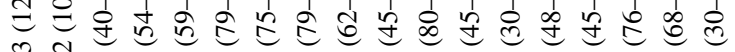

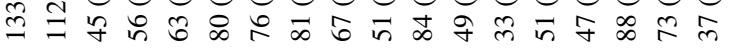

\section{ถิ)}

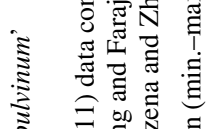

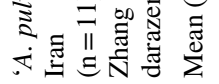

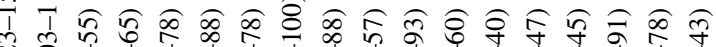
¿

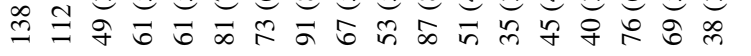

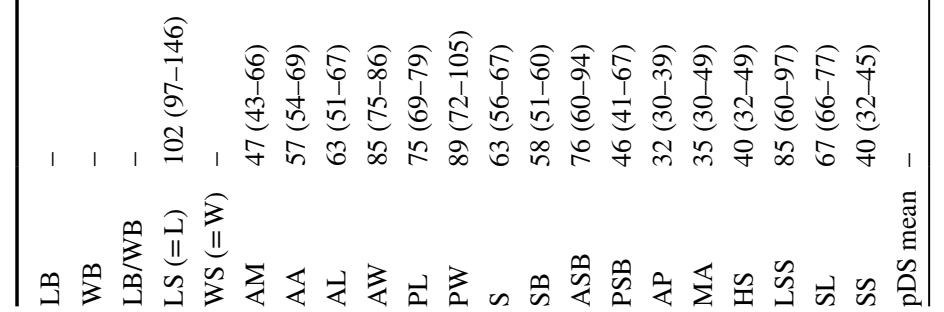




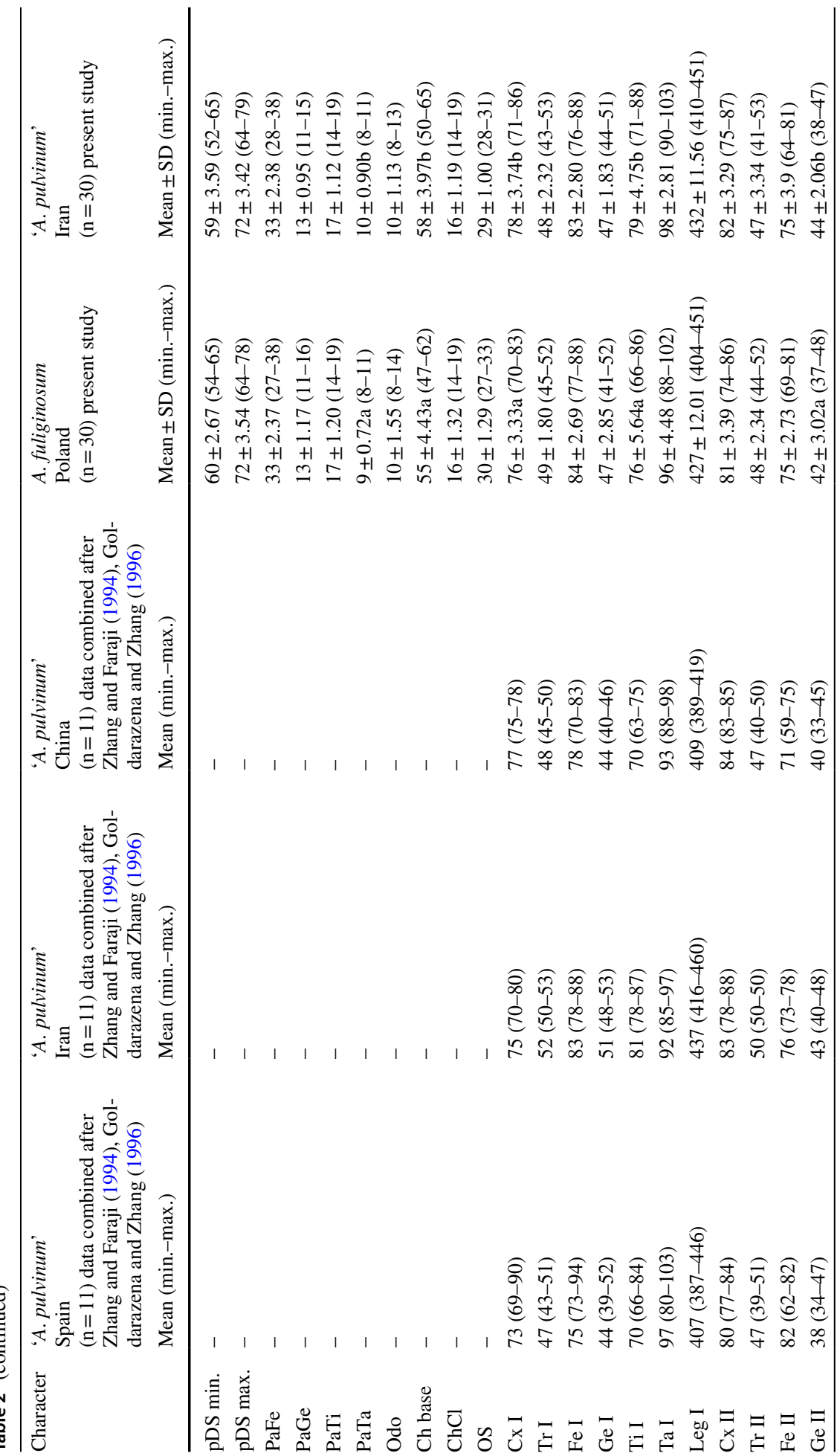




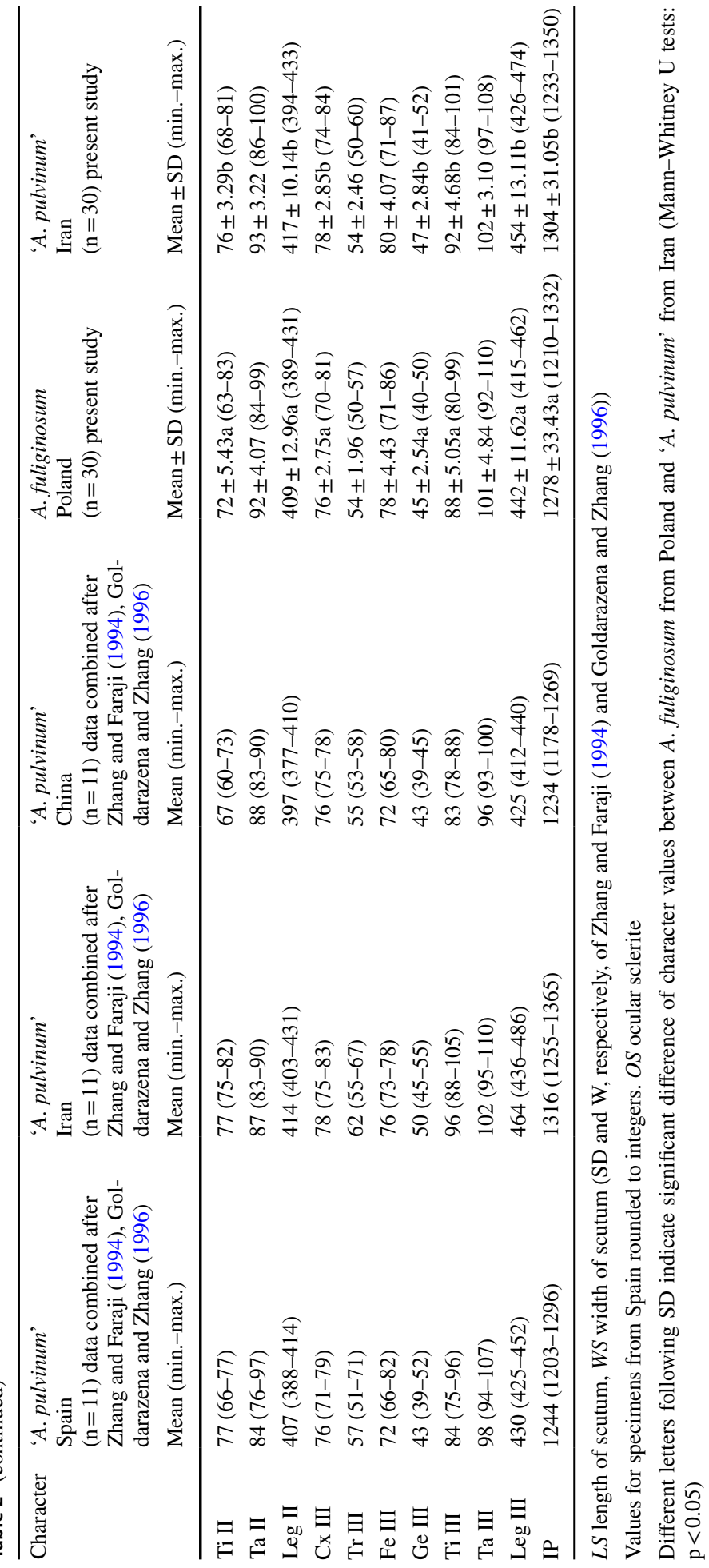


Table 3 Morphometric data on active post-larval forms of Allothrombium fuliginosum from Poland and 'A. pulvinum' from Iran (present study). The character abbreviations are explained in Mąkol (2005)

\begin{tabular}{|c|c|c|c|c|}
\hline Character & $\mathrm{n}$ & $\begin{array}{l}\text { A. fuliginosum } \\
\text { Mean } \pm \text { SD (min.-max.) }\end{array}$ & $\mathrm{n}$ & $\begin{array}{l}\text { 'A. pulvinum' } \\
\text { Mean } \pm \mathrm{SD} \text { (min.-max.) }\end{array}$ \\
\hline LB & 15 & $2608 \pm 326.62(2174-3127)$ & 13 & $2727 \pm 338.63(2160-3172)$ \\
\hline WB & 15 & $1967 \pm 277.6(1644-2435)$ & 13 & $1789 \pm 236.47(1427-2131)$ \\
\hline $\mathrm{LB} / \mathrm{WB}$ & 15 & $1.29 \pm 0.13 \mathrm{a}(1.1-1.6)$ & 13 & $1.53 \pm 0.17 \mathrm{~b}(1.3-2.0)$ \\
\hline $\mathrm{PaTa}$ & 15 & $209 \pm 17.01 \mathrm{a}(180-236)$ & 15 & $194 \pm 12.80 \mathrm{~b}(170-210)$ \\
\hline Odo & 15 & $120 \pm 11.68 \mathrm{a}(101-139)$ & 13 & $111 \pm 6.72 b(98-121)$ \\
\hline $\mathrm{ChCl}$ & 15 & $91 \pm 8.32(80-103)$ & 15 & $88 \pm 6.27(76-96)$ \\
\hline CML & 15 & $461 \pm 33.48(420-535)$ & 15 & $436 \pm 18.41(403-465)$ \\
\hline S & 11 & $236 \pm 23.43 a(206-267)$ & 13 & $211 \pm 11.15 b(191-228)$ \\
\hline SB & 15 & $100 \pm 12.52(82-116)$ & 15 & $97 \pm 7.97(85-111)$ \\
\hline $\mathrm{aPr}$ & 15 & $163 \pm 24.71(122-198)$ & 15 & $155 \pm 13.95(132-176)$ \\
\hline $\mathrm{pPr}$ & 15 & $97 \pm 8.79(85-114)$ & 15 & $100 \pm 9.24(86-111)$ \\
\hline pDS min. & 15 & $75 \pm 3.78 \mathrm{a}(69-82)$ & 15 & $68 \pm 8.77 b(51-79)$ \\
\hline pDS max. & 15 & $100 \pm 2.64 \mathrm{a}(97-105)$ & 15 & $94 \pm 5.80 \mathrm{~b}(83-104)$ \\
\hline OP & 15 & $124 \pm 8.41 \mathrm{a}(113-141)$ & 15 & $116 \pm 7.35 b(105-128)$ \\
\hline pVS & 15 & $57 \pm 4.62(52-68)$ & 15 & $60 \pm 4.55(54-68)$ \\
\hline GOP (L) & 15 & $346 \pm 26.63(290-393)$ & 15 & $339 \pm 16.08(313-362)$ \\
\hline GOP $(W)$ & 15 & $214 \pm 30.70 \mathrm{a}(150-256)$ & 14 & $192 \pm 20.93 b(161-229)$ \\
\hline $\mathrm{GOP}(\mathrm{L} / \mathrm{W})$ & 15 & $1.65 \pm 0.29(1.1-2.3)$ & 14 & $1.8 \pm 0.21(1.5-2.1)$ \\
\hline Cx I & 15 & $450 \pm 24.01(400-475)$ & 14 & $455 \pm 21.19(407-487)$ \\
\hline $\operatorname{Tr} I$ & 15 & $265 \pm 15.94 \mathrm{a}(239-290)$ & 15 & $229 \pm 18.94 b(210-264)$ \\
\hline $\mathrm{bFe} I$ & 15 & $316 \pm 20.49 a(285-350)$ & 15 & $283 \pm 16.51 \mathrm{~b}(256-306)$ \\
\hline $\mathrm{tFe} I$ & 15 & $362 \pm 21.76 \mathrm{a}(322-392)$ & 15 & $321 \pm 23.49 b(287-351)$ \\
\hline Ge I & 15 & $482 \pm 33.90 \mathrm{a}(423-520)$ & 15 & $430 \pm 28.16 b(385-483)$ \\
\hline Ti I & 15 & $481 \pm 33.79 \mathrm{a}(435-528)$ & 14 & $452 \pm 23.59 b(415-492)$ \\
\hline $\mathrm{Ta} \mathrm{I}(\mathrm{L})$ & 15 & $508 \pm 38.57 \mathrm{a}(445-554)$ & 13 & $478 \pm 20.44 b(449-515)$ \\
\hline Ta I (W) & 15 & $182 \pm 18.88(155-225)$ & 13 & $174 \pm 13.05(148-187)$ \\
\hline Leg I & 15 & $2865 \pm 163.46(2582-3050)$ & 13 & $2833 \pm 115.82(2604-2969)$ \\
\hline Cx II & 15 & $340 \pm 18.18 \mathrm{a}(312-370)$ & 13 & $297 \pm 10.40 \mathrm{~b}(282-313)$ \\
\hline Tr II & 15 & $184 \pm 12.54 \mathrm{a}(170-205)$ & 15 & $153 \pm 10.36 \mathrm{~b}(140-172)$ \\
\hline $\mathrm{bFe}$ II & 15 & $202 \pm 12 \mathrm{a}(185-220)$ & 15 & $191 \pm 12.76 b(167-210)$ \\
\hline $\mathrm{tFe} I I$ & 15 & $195 \pm 14.37 \mathrm{a}(172-215)$ & 15 & $173 \pm 15.16 \mathrm{~b}(148-198)$ \\
\hline Ge II & 15 & $258 \pm 16.42 \mathrm{a}(230-290)$ & 15 & $234 \pm 16.24 b(204-266)$ \\
\hline Ti II & 15 & $293 \pm 22.69 \mathrm{a}(262-335)$ & 15 & $274 \pm 15.29 b(251-298)$ \\
\hline Ta II (L) & 15 & $386 \pm 21.32 \mathrm{a}(340-414)$ & 15 & $368 \pm 15.70 b(335-387)$ \\
\hline Leg II & 15 & $1859 \pm 94.85 \mathrm{a}(1702-2027)$ & 14 & $1686 \pm 53.86 \mathrm{~b}(1596-1788)$ \\
\hline Cx III & 15 & $274 \pm 21.94 \mathrm{a}(233-307)$ & 14 & $252 \pm 11.42 b(235-277)$ \\
\hline Tr III & 15 & $169 \pm 15.03 a(142-190)$ & 15 & $145 \pm 10.01 b(131-160)$ \\
\hline bFe III & 15 & $194 \pm 13.36 \mathrm{a}(165-220)$ & 15 & $170 \pm 11.51 \mathrm{~b}(155-187)$ \\
\hline $\mathrm{tFe}$ III & 15 & $176 \pm 12.98 \mathrm{a}(150-196)$ & 14 & $159 \pm 9.98 b(145-176)$ \\
\hline Ge III & 15 & $242 \pm 17.15 \mathrm{a}(217-278)$ & 14 & $225 \pm 15.41 \mathrm{~b}(199-253)$ \\
\hline Ti III & 15 & $280 \pm 20.77(245-315)$ & 14 & $266 \pm 18.82(236-289)$ \\
\hline Ta III (L) & 15 & $354 \pm 21.95(320-385)$ & 14 & $346 \pm 15.56(311-376)$ \\
\hline Leg III & 15 & $1689 \pm 97.53 \mathrm{a}(1503-1853)$ & 14 & $1563 \pm 64.85 \mathrm{~b}(1426-1665)$ \\
\hline
\end{tabular}


Table 3 (continued)

\begin{tabular}{lllll}
\hline Character & $\mathrm{n}$ & $\begin{array}{l}\text { A. fuliginosum } \\
\text { Mean } \pm \text { SD (min.-max.) }\end{array}$ & $\mathrm{n}$ & $\begin{array}{l}\text { 'A. pulvinum' } \\
\text { Mean } \pm \text { SD (min.-max.) }\end{array}$ \\
\hline Cx IV & 15 & $355 \pm 26.69 \mathrm{a}(312-398)$ & 14 & $322 \pm 13.05 \mathrm{~b}(290-338)$ \\
Tr IV & 15 & $213 \pm 18.12 \mathrm{a}(183-245)$ & 15 & $175 \pm 10.22 \mathrm{~b}(159-194)$ \\
bFe IV & 15 & $239 \pm 16.53 \mathrm{a}(210-276)$ & 15 & $216 \pm 15.28 \mathrm{~b}(178-237)$ \\
tFe IV & 15 & $251 \pm 16.47 \mathrm{a}(225-288)$ & 15 & $238 \pm 15.39 \mathrm{~b}(216-262)$ \\
Ge IV & 15 & $336 \pm 23.70(305-390)$ & 15 & $324 \pm 20.84(287-357)$ \\
Ti IV & 15 & $381 \pm 31.73(345-462)$ & 15 & $378 \pm 23.93(323-412)$ \\
Ta IV (L) & 15 & $424 \pm 30.04(375-484)$ & 15 & $412 \pm 19.88(374-437)$ \\
Leg IV & 15 & $2200 \pm 136.85 \mathrm{a}(1984-2524)$ & 15 & $2065 \pm 92.53 \mathrm{~b}(1839-2191)$ \\
IP & 15 & $8613 \pm 472.13 \mathrm{a}(7833-9421)$ & 15 & $8167 \pm 257.06 \mathrm{~b}(7655-8520)$ \\
\hline
\end{tabular}

$O P$ eye peduncle

Different letters following SD indicate significant difference of character values between A. fuliginosum from Poland and 'A. pulvinum' from Iran (Mann-Whitney U tests: $\mathrm{p}<0.05$ )

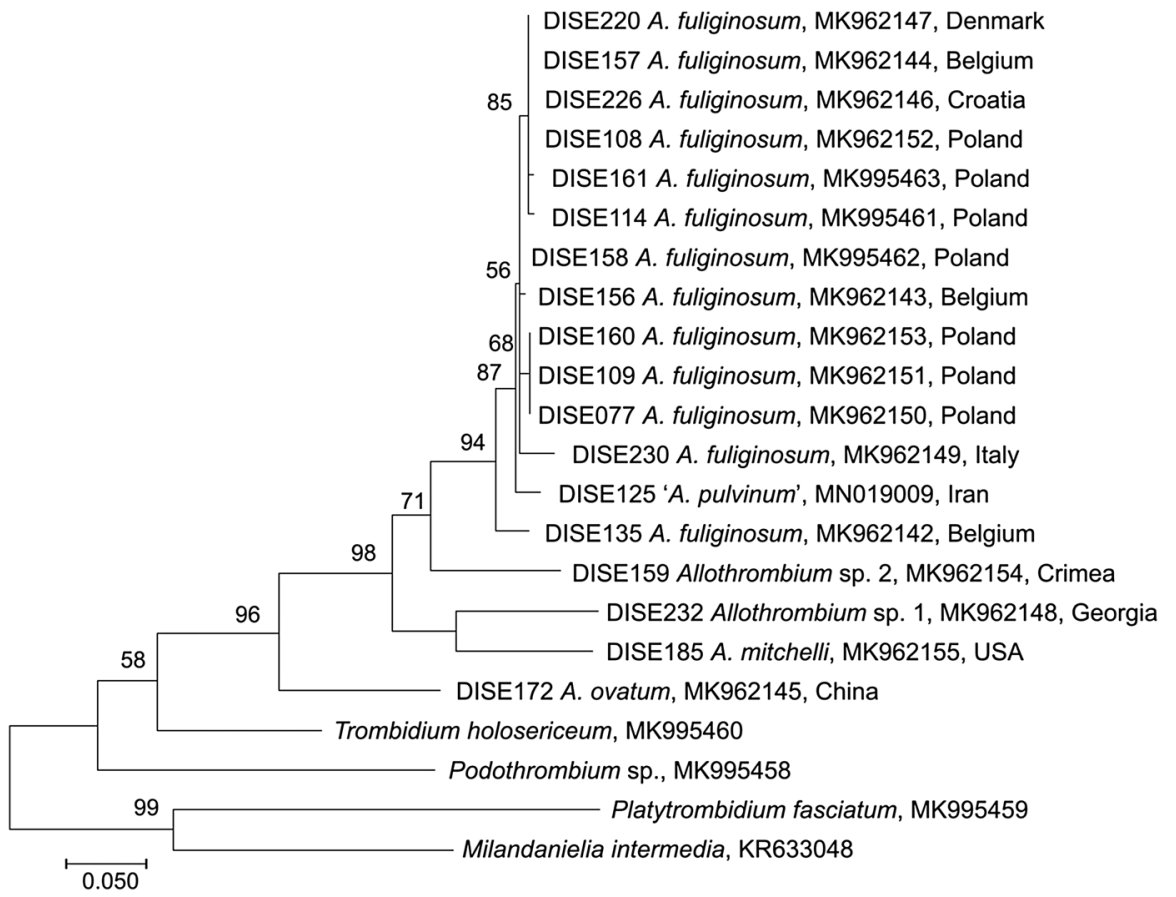

Fig. 1 COI bootstrap original tree, analysis by ML method, sequences 409 bp long

sp. 2 collected in Crimea, $16.1-17.3 \%$ in relation to A. mitchelli, 19.1-20.5\% in relation to Allothrombium sp. 1 collected in Georgia and $22.4-24.5 \%$ in relation to A. ovatum (Supplementary Table S2). 


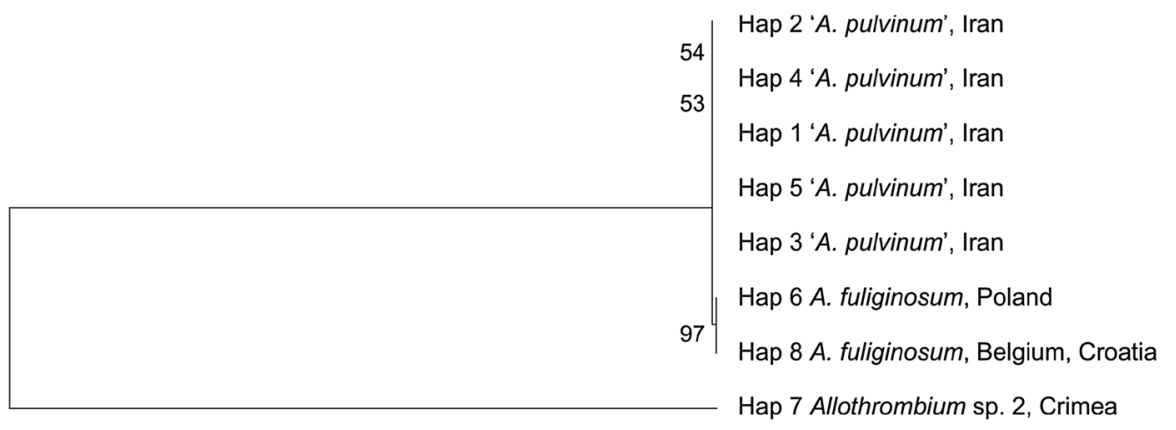

5

Fig. 2 ITS2 bootstrap original tree, analysis by ML method, sequences 514 bp long. Hap=haplotype

The genetic distance (K2P) in the ITS2 region for specimens representing A. fuliginosum and 'A. pulvinum' was 0-0.2\% (Supplementary Table S4), whereas for 'A. pulvinum' (after Khalili Mahani et al. 2009) it attained the range 0-0.5\% (Supplementary Table S5). The distance between the European A. fuliginosum and Iranian 'A. pulvinum' (sequence DISE125) amounting at $1.7-1.9 \%$, was about $10 \times$ lower than the distance $(17.9-18.9 \%)$ between A. fuliginosum + 'A. pulvinum' clade and Allothrombium sp. 2 collected in Crimea (Supplementary Table 4). The putative interspecific variation between specimens preliminarily assigned to both nominal species (A. fuliginosum, 'A. pulvinum') was slightly higher than the magnitude of intraspecific variation, calculated independently for each 'species'.

The overall low value of genetic distance between the nucleotide sequences obtained from A. fuliginosum and from specimens preliminarily assigned to 'A. pulvinum' originating from the Palaearctic (COI: 1.7-3.8\%; ITS2: 1.7-1.9\%), along with the lack of well supported differences in morphological traits, militate in favor of recognizing the common species identity of both.

\section{Discussion}

The complex taxonomic situation within the genus Allothrombium, with special reference to taxa inhabiting the same geographic units, has resulted mainly from insufficiency of reliable morphological characters that allow species discrimination. The limited knowledge of intraspecific variation constitutes the main obstacle in studies on the biology of species and their use in biological control.

Several authors referred to the problem related to morphology-based discrimination of Allothrombium spp., with special reference to A. fuliginosum and A. pulvinum. The first description of A. pulvinum larvae was provided by Howard (1918), based on material collected in Minnesota, USA. Zhang and Xin (1989b), when listing detailed characteristics of larvae collected in China, referred to the presence of four setae on femur II, contrary to five setae reported earlier by Robaux (1974) for A. fuliginosum. It is noteworthy that Robaux (1974) pointed to the presence of five setae on femur II in A. fuliginosum, whereas in the drawing accompanying the description (Fig. 12 in Robaux 1974) four setae are shown. Nevertheless, the difference in the character state (5 vs. 4 setae on femur II) was followed also by subsequent authors (Zhang and Xin 1992; Zhang and Faraji 1994; Zhang 
and Norbakhsh 1995) as a criterion to distinguish between larvae of A. fuliginosum and A. pulvinum. At the same time, due to much less attention paid to active post-larval forms, no differences between deutonymphs and adults of potentially distinct species have been depicted.

Zhang (1996), in his comprehensive study on parasitism of aphids by larvae of Allothrombium, stated that A. pulvinum from USA and UK, both examined by the author (Zhang 1991, 1996), differed in some morphological measurements and that their biology and host relations might also differ. Zhang and Faraji (1994) compared the specimens of $A$. pulvinum from China with those collected for the first time in Iran and attributed the metric differences in some quantitative traits to intraspecific geographical variation. Zhang and Xin (1992) and Zhang (1996) claimed that what was reported as A. fuliginosum may actually be a mixture of several species, whereas Wohltmann and Mąkol (2009) considered the larvae of A. pulvinum and of yet another species, Allothrombium reinholdi Haitlinger, as falling within the variability range of $A$. fuliginosum.

The question of separate identity of $A$. fuliginosum and $A$. pulvinum became the subject of long-lasting dispute. Having in mind the necessity to refer to type material of $A$. pulvinum, originating from the Nearctic for purpose of possible synonymisation, another question has been posed of likely misidentification of specimens actually representing $A$. fuliginosum, recorded in the Palaearctic.

During our examination of A. fuliginosum from the Western Palaearctic we have not come across larval specimens with five setae on femur II and only in one specimen originating from Iran and preliminarily assigned to A. pulvinum, the asymmetrical state $(5 n / 4 n)$ in chaetotaxy of femur II was observed, most likely caused by some developmental malformation. The larvae of A. fuliginosum revealed high consistency of meristic traits with larvae assigned to A. pulvinum, examined by Zhang and Faraji (1994).

The reference to morphology-based identification of species, at limited knowledge of intraspecific variation, but also in view of possible misidentifications caused by the paucity of diagnostic traits, has blurred the inference on species borders and has stimulated the application of molecular methods. Moreover, the molecular evidence allows to avoid false inference related to characters which display phenotypic plasticity. However, despite the recently intensified efforts made at ascertaining species limits by means of molecular methods, identification still largely depends on morphology.

COI and ITS2 markers have been commonly applied as DNA barcodes (e.g. Navajas et al. 1992, 1994, 1996; Ben-David et al. 2007; Xie et al. 2008; Yao et al. 2010) to assess genetic variation and to find differences between species and strains that cannot be distinguished on the basis of morphological features. The method has been hitherto applied to a different extent in relation to various systematic groups and, at the same time, the diversified criteria for taxa discrimination have been adopted. Hebert et al. (2004) proposed a 10× rule, being the $10 \times$ average intraspecific difference between COI sequences that can sanction provisional species distinction. Smith et al. (2005) considered the COI sequence divergence threshold of 3\% for Molecular Operational Taxonomic Unit (MOTU) as adequate for morphologically defined species.

Yang et al. (2011) reported an intraspecific distance up to $3 \%$ in COI and up to $7.8 \%$ in ITS2 at identification of six species of astigmatid mites in China. Ben-David et al. (2007) used a 2\% threshold in ITS2 sequence to confirm the separate identity of species assigned to Tetranychus spp. and claimed that nucleotide divergence of 1-2\% should be treated carefully and involve the confirmation of species identity by morphological criteria. The low nucleotide divergence of 1.7\% (Gotoh et al. 1998), 2.5 and 1.2\% (Navajas et al. 1997) between other morphologically similar Tetranychus spp., supported 
by detailed morphological analyses and crossing experiments, confirmed the separate identity of species. Despite several attempts made to establish a standard limit between intra- and interspecific difference, none of the limits can be generalized to many groups of organisms (Puillandre et al. 2012).

A survey of Khalili Mahani et al. (2009), who investigated genetic variation of $A$. pulvinum in Iran by COI and ITS2 sequences, revealed that at least two geographically distinct populations or even more than one species are represented in the material. No corresponding studies on genetic variation of A. fuliginosum have been carried out until present. Due to the fact that different primers for COI amplification were used by Khalili Mahani et al. (2009) and in the present study, only a direct comparison of ITS2 sequences between A. fuliginosum and 'A. pulvinum' was possible. In our study, with the application of phylogenetic tree method for COI sequences, a specimen of ' $A$. pulvinum' (DISE125, Iran) was located in the clade containing specimens of A. fuliginosum. The intraspecific nucleotide divergence for A. fuliginosum + 'A. pulvinum' based on ITS2 sequences obtained from geographically distinct populations ranged from 1.7 to $1.9 \%$.

The data on two or more nominal species which, based on molecular evidence, have overlapping variability ranges and thus their names become synonyms, are still scarce, contrary to the increasing research effort devoted to cryptic species in mites (e.g. Skoracka and Dabert 2010; Skoracka et al. 2012, 2015; Tixier et al. 2006, 2017).

Our study corroborates the variously developed and interpreted criteria and, again, illustrates the necessity of an integrative taxonomic approach. Two hypotheses could be proposed here: (i) specimens representing the Palaearctic populations of A. fuliginosum and 'A. pulvinum' belong to the same species which is characterised by relatively high molecular polymorphisms, and (ii) specimens assigned to A. fuliginosum and 'A. pulvinum' represent distinct, however closely related species. In case of (ii), the common identity of $A$. pulvinum from the Nearctic and of Palaearctic members of 'A. pulvinum' should be confirmed in future studies, based on molecular methods. The present survey does not allow an answer to the question whether both A. fuliginosum and A. pulvinum are present in Iran. However, the common species identity of specimens collected in Europe and in Asia (Iran), is also supported by inference made by Zhang and Faraji (1994) on conspecificity of material ('A. pulvinum') originating from China and Iran.

In conclusion, we hypothesize that $A$. fuliginosum is a species widely distributed in the Palaearctic. The wide host spectrum reported for larvae of A. fuliginosum (Zhang 1996 for A. pulvinum collected in England; Felska et al. 2018) allows to place the species among generalists. Similarly, an even wider array of hosts has been hitherto reported for A. pulvinum (Felska et al. 2018); however, due to the questioned occurrence of the species in the Palaearctic, the records from the eastern hemisphere may actually expand the list of hosts known for A. fuliginosum. The differences in metric data (already pointed to by Zhang and Faraji 1994), but also the slight shift in phenology of specimens originating from different populations of A. fuliginosum collected within the Palaearctic realm, should be attributed to geographical variation.

Acknowledgements We thank Nathalie Brenard (Department of Biology, University of Antwerp, Belgium), Yuri M. Marusik (Institute for Biological Problems of the North RAS, Magadan, Russia), Galina N. Antipova (Magadan, Russia), Cal Welbourn (Florida Department of Agriculture and Consumer Services, Gainesville, FL, USA), Heinrich Schatz (Institute of Ecology and Institute of Zoology, University of Innsbruck, Austria), Marek Wanat (Museum of Natural History, University of Wrocław, Poland), Elżbieta Kowalska, Jarosław Proćków, Joanna Łaydanowicz, Aleksandra Kłosińska, Agnieszka Piróg, Kinga Gardziejewska, Marta Konikiewicz and Bartosz Beszterda (Department of Invertebrate Systematics and Ecology, 
Wrocław University of Environmental and Life Sciences, Poland) for providing material for study. We are also grateful to two anonymous reviewers for their valuable comments.

Open Access This article is distributed under the terms of the Creative Commons Attribution 4.0 International License (http://creativecommons.org/licenses/by/4.0/), which permits unrestricted use, distribution, and reproduction in any medium, provided you give appropriate credit to the original author(s) and the source, provide a link to the Creative Commons license, and indicate if changes were made.

\section{References}

Ben-David T, Melamed S, Gerson U (2007) ITS2 sequences as barcodes for identifying and analyzing spider mites (Acari: Tetranychidae). Exp Appl Acarol 41:169-181. https://doi.org/10.1007/s1049 3-007-9058-1

Chen PR, Zhang Z-Q (1991) Biology of Allothrombium pulvinum Ewing (Acari: Trombidiidae) and its impact on two spotted spider mite (Acari: Tetranychidae) in cotton fields. J Appl Entomol 112:3137. https://doi.org/10.1111/j.1439-0418.1991.tb01025.x

Dabert M, Witaliński W, Kaźmierski A, Olszanowski Z, Dabert J (2010) Molecular phylogeny of acariform mites (Acari, Arachnida): strong conflict between phylogenetic signal and long-branch attraction artifacts. Mol Phylogenet Evol 56:222-241. https://doi.org/10.1016/j.ympev.2009.12.020

Ewing HE (1917) New Acarina, part II-description of new species and varieties from Iowa, Missouri, Illinois, Indiana, and Ohio. Bull Am Mus Nat Hist 37:149-173

Feider Z (1951) Un trombidiid dusman al puricilor de plante. Stud şi Cerc (Biol şi Şt Agr) Acad RPR, filiala Iaşi 2:480-497

Felska M, Mąkol J (2015) Morphological and molecular characteristics of Milandanielia intermedia (Feider, 1950) (Trombidiformes: Microtrombidiidae) with data on its biology and ecology. Zootaxa 4007:29-46. https://doi.org/10.11646/zootaxa.4007.1.2

Felska M, Wohltmann A, Mąkol J (2018) A synopsis of host-parasite associations between Trombidioidea (Trombidiformes: Prostigmata, Parasitengona) and arthropod hosts. Syst Appl Acarol 23:1375-1479. https://doi.org/10.11158/saa.23.7.14

Goldarazena A, Zhang Z-Q (1996) Notes on Allothrombium pulvinum (Acari: Trombidiidae), a species new to the fauna of Spain. Syst Appl Acarol 1:209-212. https://doi.org/10.11158/saa.1.1.27

Gotoh T, Gutierrez J, Navajas M (1998) Molecular Comparison of the Sibling Species Tetranychus pueraricola Ehara et Gotoh and T. urticae Koch (Acari: Tetranychidae). Entomol Sci 1:55

Hebert PDN, Stoeckle MY, Zemlak TS, Francis CM (2004) Identification of birds through DNA barcodes. PLoS Biol 2:e312. https://doi.org/10.1371/journal.pbio.0020312

Henking H (1882) Beitrage zur Anatomie, Entwicklungsgesschichte und Biologie von Trombidium fuliginosum Herm. Zwiss Zool 37:553-663

Hirst S (1926) Note on the development of Allothrombium fuliginosum Hermann. J R Microsc Soc 46:274-276

Howard CW (1918) A preliminary report on the Trombidiidae of Minnesota. Ruggles AG. Seventeenth Report, State Entomologist of Minnesota, pp 111-144

Huelsenbeck JP, Ronquist F (2001) MRBAYES: Bayesian inference of phylogeny. Bioinformatics 17:754-755

Khalili Mahani M, Inomata N, Saboori A, Tabatabaei BES, Ishiyama H, Ariana A, Szmidt AE (2009) Genetic variation in populations of Allothrombium pulvinum (Acari: Trombidiidae) from Northern Iran revealed by mitochondrial coxI and nuclear rDNA ITS2 sequences. Exp Appl Acarol 48:273289. https://doi.org/10.1007/s10493-009-9241-7

Kimura M (1980) A simple method for estimating evolutionary rate of base substitutions through comparative studies of nucleotide sequences. J Mol Evol 16:111-120

Kumar S, Stecher G, Tamura K (2016) MEGA7: molecular evolutionary genetics analysis version 7.0 for bigger datasets. Mol Biol Evol 33:1870-1874. https://doi.org/10.1093/molbev/msw054

Mąkol J (2005) Trombidiidae (Acari: Actinotrichida: Trombidioidea) of Poland. Fauna Poloniae. Museum and Institute of Zoology, Polish Academy of Sciences \& Natura Optima Dux Foundation, Warsaw, pp 1-259

Mąkol J, Wohltmann A (2012) An annotated checklist of terrestrial Parasitengona (Actinotrichida: Prostigmata) of the World, excluding Trombiculidae and Walchiidae. Ann Zool 62:359-562. https://doi. org/10.3161/000345412X656671 
Moniuszko H, Zaleśny G, Mąkol J (2015) Host-associated differences in morphometric traits of parasitic larvae Hirsutiella zachvatkini (Actinotrichida: Trombiculidae). Exp Appl Acarol 67:123-133. https ://doi.org/10.1007/s10493-015-9925-0

Moss WW (1962a) Studies on the morphology of the trombidiid mite Allothrombium lerouxi Moss (Acari). Acarologia 4:313-345

Moss WW (1962b) The immature stages of the red velvet mite Allothrombium lerouxi (Acari: Trombidiidae). Ann Entmol Soc Am 55:295-303

Muñoz-Cárdenas K, Fuentes-Quintero LS, Rueda-Ramirez D, Rodríguez CD, Cantor RF (2015) The Erythraeoidae (Trombidiformes: Prostigmata) as biological control agents, with special reference to Balaustium. In: Carrillo D, de Moraes GJ, Peña JE (eds) Prospects for biological control of plant feeding mites and other harmful organisms, progress in biological control, vol 19. Springer, Basel (CH), pp 207-239

Navajas M, Cotton D, Kreiter S, Gutierrez J (1992) Molecular approach in spider mites (Acari: Tetranychidae): preliminary data on ribosomal DNA sequences. Exp Appl Acarol 15:211-218

Navajas M, Gutierrez J, Bonato O, Bolland HR, Mapangou-Divasa S (1994) Intraspecific diversity of the cassava green mite Mononychellus progresivus (Acari: Tetranychidae) using comparisons of mitochondrial and nuclear ribosomal DNA sequences and cross-breeding. Exp Appl Acarol 18:351-360

Navajas M, Gutierrez J, Boursot P (1996) Mitochondrial cytochrome oxidase I in tetranychid mites: a comparison between molecular phylogeny and changes of morphological and life history traits. Bull Entomol Res 86:407-417. https://doi.org/10.1017/S0007485300034994

Navajas M, Gutierrez J, Gotoh T (1997) Convergence of molecular and morphological data reveals phylogenetic information in Tetranychus species and allows the restoration of the genus Amphitetranychus (Acari: Tetranychidae). Bull Entomol Res 87:283-288. https://doi.org/10.1017/S000748530 0037238

Puillandre N, Lambert A, Brouillet S, Achaz G (2012) ABGD, automatic barcode gap discovery for primary species delimitation. Mol Ecol 21:1864-1877. https://doi.org/10.1111/j.1365-294X.2011.05239.x

Robaux P (1974) Recherches sur le développement et la biologie des acariens 'Thrombidiidae'. Mém Mus Natl Hist Nat, Paris (n. s.), Sér A. Zoologie 85:1-186

Robaux P, Aeschlimann JP (1987) Allothrombium monspessulanum nov. spec. (Acari: Trombidiidae), un important ennemi naturel des arthropodes inféodés à la luzerne cultivée (Medicago sativa Linnaeus) en région méditerranéenne. Mitt Schweiz Ent Ges 60:43-50

Rozas J, Ferrer-Mata A, Sánchez-DelBarrio JC, Guirao-Rico S, Librado P, Ramos-Onsins SE, SánchezGracia A (2017) DnaSP 6: DNA sequence polymorphism analysis of large datasets. Mol Biol Evol 34:3299-3302. https://doi.org/10.1093/molbev/msx248

Saboori A, Kamali K (2000) Description of Allothrombium triticium adult (Acari: Trombidiidae) from Iran. Syst Appl Acarol 5:207-208. https://doi.org/10.11158/saa.5.1.24

Saboori A, Zhang Z-Q (1996) Biology of Allothrombium pulvinum Ewing (Acari: Trombidiidae) in West Mazandran. Iran. Exp Appl Acarol 20:137-142

Saboori A, Zhang Z-Q (1997) Description of Allothrombium shirazicum deutonymph (Acari: Trombidiidae) from Iran. Syst Appl Acarol 2:251-252. https://doi.org/10.11158/saa.4.1.28

Skoracka A, Dabert M (2010) The cereal rust mite Abacarus hystrix (Acari: Eriophyoidea) is a complex of species: evidence from mitochondrial and nuclear DNA sequences. Bull Entomol Res 100:263272. https://doi.org/10.1017/S0007485309990216

Skoracka A, Kuczyński L, de Mendonca R, Dabert M, Szydło W, Knihinicki D, Truol G, Navia D (2012) Cryptic species within the wheat curl mite Aceria tosichella (Keifer) (Acari, Eriophyoidea) revealed by mitochondrial, nuclear and morphometric data. Invertebr Syst 26:417-433

Skoracka A, Magalhaẽs S, Rector BG, Kuczyński L (2015) Cryptic speciation in the Acari: a function of species lifestyles or our ability to separate species? Exp Appl Acarol 67:165-182. https://doi. org/10.1007/s10493-015-9954-8

Smith MA, Fisher BL, Hebert PDN (2005) DNA barcoding for effective biodiversity assessment of a hyperdiverse arthropod group: the ants of Madagascar. Philos Trans R Soc Lond B Biol Sci 360:1825-1834. https://doi.org/10.1098/rstb.2005.1714

Šundić M, Pajović I (2012) Seasonal abundance and host preference by Allothrombium pulvinum Ewing (1917) (Acari: Trombidiidae) larvae on aphids (Homoptera: Aphididae) of Montenegro, with notes on rate of parasitism and new metric data. Agric For 56:85-94. https://doi.org/10.17707/AgricultForest

Tixier M-S, Kreiter S, Barbar Z, Ragusa S, Cheval B (2006) Status of two cryptic species, Typhlodromus exhilaratus Ragusa and Typhlodromus phialatus Athias-Henriot (Acari: Phytoseiidae): consequences for taxonomy. Zool Scr 35:115-122. https://doi.org/10.1111/j.1463-6409.2006.00222.x 
Tixier M-S, Dos Santos Vicente V, Douin M, Duso C, Kreiter S (2017) Great molecular variation within the species Phytoseius finitimus (Acari: Phytoseiidae): implications for diagnosis decision within the mite family Phytoseiidae. Acarologia 57:493-515. https://doi.org/10.24349/acarologia/20174168

Welbourn WC (1983) Potential use of trombidioid and erythraeoid mites as biological control agents of insect pests. In: Hoy MA, Cunningham GL, Knutson L (eds) Biological control of pests by mites, vol 3304. Agric Exp Stn, Div Agric Nat Res, Univ Calif, Berkeley, pp 103-140 (Special Publication)

Wohltmann A, Mąkol J (2009) A redescription of Allothrombium meridionale Berlese, 1910 (Acari: Trombidiformes: Trombidioidea) with notes on biology and developmental malformations. Ann Zool 59:397-413. https://doi.org/10.3161/000345409X476468

Xie L, Xie R-R, Zhang K-J, Hong X-Y (2008) Genetic relationship between the carmine spider mite Tetranychus cinnabarinus (Boisduval) and the two-spotted mite T. urticae Koch in China based on the mtDNA COI and rDNA ITS2 sequences. Zootaxa 1726:18-32

Yang B, Cai J, Cheng X (2011) Identification of astigmatid mites using ITS2 and COI regions. Parasitol Res 108:497-503. https://doi.org/10.1007/s00436-010-2153-y

Yao H, Song J, Liu C, Luo K, Han J, Li Y, Pang X, Xu H, Zhu Y, Xiao P, Chen S (2010) Use of ITS2 region as the universal DNA barcode for plants and animals. PLOS ONE 5(10):e13102. https://doi. org/10.1371/journal.pone.0013102

Zhang Z-Q (1988) Two common mites of Allothrombium Berlese in China. Kunchong zhishi (Insect Knowledge) $25: 172-174$

Zhang Z-Q (1991) Parasitism of Acyrthosiphon pisum by Allothrombium pulvinum (Acariformes: Trombidiidae): host attachment site, host size selection, superparasitism and effect on host. Exp Appl Acarol 11:137-147. https://doi.org/10.1007/BF01246086

Zhang Z-Q (1992) Notes on the occurrence and distribution of the biocontrol agent, Allothrombium pulvinum Ewing (Acari, Trombidiidae), in a peach orchard in China. J Appl Ent 113:13-17. https://doi. org/10.1111/j.1439-0418.1992.tb00632.x

Zhang Z-Q (1996) Parasitism of aphids (Homoptera: Aphididae) by larvae of Allothrombium pulvinum (Acari: Trombidiidae): host species selection, host size selection, and superparasitism. Syst Appl Acarol 1:55-63

Zhang Z-Q (1998) Biology and ecology of trombidiid mites (Acari: Trombidioidea). Exp Appl Acarol 22:139-155. https://doi.org/10.1007/978-94-017-1343-6_19

Zhang Z-Q (2010) Terrestrial Parasitengona (except chiggers) of China: a review of progress in systematics and biology, with a checklist of species. In: Zhang Z-Q, Hong X-Y, Fan Q-H (eds) Xin Jie-Liu centenary: Progress in Chinese acarology. Zoosymposia 4:94-105

Zhang Z-Q, Chen P (1993) Parasitism of Aphis gossypii (Homoptera: Aphididae) by Allothrombium pulvinum larvae (Acari: Trombidiidae) in cotton fields: spatial dispersion and density dependence. Exp Appl Acarol 17:905-912

Zhang Z-Q, Faraji F (1994) Notes on Allothrombium pulvinum (Acari: Trombidiidae) new to the fauna of Iran. Acarologia 35:357-360

Zhang Z-Q, Norbakhsh H (1995) A new genus and three new species of mites (Acari: Trombidiidae) described from larvae ectoparasitic on aphids from Iran. Eur J Entomol 92:705-718

Zhang Z-Q, Xin JL (1989a) Biology of Allothrombium pulvinum (Acariformes: Trombidiidae), a potential biological control agent of aphids in China. Exp Appl Acarol 11:101-108

Zhang Z-Q, Xin JL (1989b) Studies on the morphology and life history of Allothrombium pulvinum Ewing (Acariformes: Trombidiidae). Acta Ent Sinica 32:192-199 (in Chinese with English abstract)

Zhang Z-Q, Xin JL (1992) Review of larval Allothrombium (Acari: Trombidioidea), with description of a new species ectoparasitic on aphids in China. J Nat Hist 26:383-393. https://doi.org/10.1080/00222 939200770211

Zhang Z-Q, Chen PR, Wang K, Wang XY (1993) Overdispersion of Allothrombium pulvinum larvae (Acari: Trombidiidae) parasitic on Aphis gossypii (Homoptera: Aphididae) in cotton fields. Ecol Entomol 18:379-384

Publisher's Note Springer Nature remains neutral with regard to jurisdictional claims in published maps and institutional affiliations. 